\title{
Outcomes and prognostic factors after pulmonary metastasectomy in patients with colorectal cancer with previously resected hepatic metastases
}

\author{
Kimihiro Shimizu, MD, $\mathrm{PhD},{ }^{\mathrm{a}}$ Yoichi Ohtaki, $\mathrm{MD}, \mathrm{PhD},{ }^{\mathrm{a}}$ Takehiro Okumura, $\mathrm{MD},{ }^{\mathrm{b}}$ \\ Narikazu Boku, MD, PhD, ${ }^{\mathrm{c}}$ Hirotoshi Horio, MD,${ }^{\mathrm{d}}$ Mitsuhiro Takenoyama, MD, PhD, \\ Motohiro Yamashita, MD, PhD, ${ }^{\mathrm{f}}$ Ichinosuke Hyodo, $\mathrm{MD}, \mathrm{PhD},{ }^{\mathrm{g}}$ Keita Mori, $\mathrm{PhD},{ }^{\mathrm{h}}$ and \\ Haruhiko Kondo, MD
}

\section{ABSTRACT}

Objectives: Outcomes and prognostic factors remain obscure in patients with colorectal cancer after pulmonary metastasectomy who had previously received a curative hepatic metastasectomy.

Methods: We collected data of 757 patients with pulmonary metastasis from colorectal cancer who underwent curative metastasectomy between 2004 and 2008 from 46 Japanese institutions, from which we extracted data on patients who previously received curative hepatic metastasectomy. Disease-free survival, overall survival, and prognostic factors were analyzed.

Results: The subjects of this study were 160 patients, of whom $44 \%$ had primary rectal tumor, $73 \%$ had a single pulmonary metastasis, $11 \%$ had a bilateral pulmonary metastasis, and 39\% had high ( $>5 \mathrm{ng} / \mathrm{mL}$ ) serum carcinoembryonic antigen. Patients' median age was 66 years, and $58 \%$ were male. The median follow-up was 64 months. Five-year overall survival and disease-free survival were $65.2 \%$ (95\% confidence interval, 56.8-72.5) and 33.5\% (95\% confidence interval, 26.1-41.0), respectively. In multivariable analyses, high prethoracotomy carcinoembryonic antigen level was an independent prognostic factor for overall survival (hazard ratio, 2.01; 95\% confidence interval, 1.16-3.47) and diseasefree survival (hazard ratio, 2.10; 95\% confidence interval, 1.41-3.12). Five-year overall survival and disease-free survival of patients with normal prethoracotomy carcinoembryonic antigen level were $76.4 \% \quad(95 \%$ confidence interval, 66.1-83.9) and 40.7\% (95\% confidence interval, 30.5-50.5), respectively.

Conclusions: After pulmonary metastasectomy, approximately two thirds of patients with colorectal cancer with a history of curative hepatic metastasectomy survived for 5 years - half of them disease-free. Our results indicate that patients with colorectal cancer with pulmonary metastasis and a history of curative hepatic metastasectomy may benefit from sequential pulmonary metastasectomy, especially if prethoracotomy serum carcinoembryonic antigen levels are within normal range. (J Thorac Cardiovasc Surg 2019;157:2049-57)

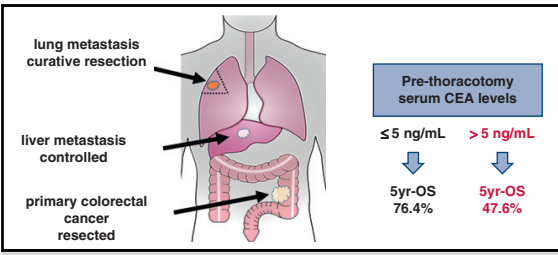

OS in patients who underwent both hepatic and pulmonary metastasectomies.

\section{Central Message}

Patients with pulmonary metastases and history of curative hepatic metastasectomy may benefit from sequential pulmonary metastasectomy, especially if prethoracotomy serum CEA levels are $5 \mathrm{ng} / \mathrm{mL}$ or less.

Perspective

Pulmonary metastasectomy can benefit patients with colorectal carcinoma, history of curative hepatic metastasectomy, and prethoracotomy serum CEA levels $5 \mathrm{ng} / \mathrm{mL}$ or less.

See Commentaries on pages 2058 and 2060.

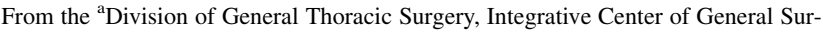
gery, Gunma University Hospital, Maebashi, Gunma, Japan; ${ }^{\mathrm{b}}$ Department of Surgery, School of Medicine, University Hospital Mizonokuchi, Teikyo University, Kanagawa, Japan; ' Division of Gastrointestinal Medical Oncology, National Cancer Center Hospital, Tokyo, Japan; ${ }^{\mathrm{d}}$ Department of Thoracic Surgery, Tokyo Metropolitan Cancer and Infectious Diseases Center Komagome Hospital, Tokyo, Japan; ${ }^{\mathrm{e}}$ Department of Thoracic Oncology, National Kyushu Cancer Center, Fukuoka, Japan; ${ }^{\mathrm{f}}$ Division of General Thoracic Surgery, Shikoku Cancer Center, Ehime, Japan; ${ }^{g}$ Division of Gastroenterology Clinical Medicine Faculty of Medicine, University of Tsukuba, Ibaraki, Japan; ${ }^{\mathrm{h}}$ Clinical Research Support Center,
}

Shizuoka Cancer Center, Shizuoka, Japan; and ${ }^{\mathrm{i}}$ General Thoracic Surgery, School of Medicine, Kyorin University, Tokyo, Japan.

Received for publication April 21, 2018; revisions received Nov 28, 2018; accepted for publication Dec 23, 2018; available ahead of print Feb 10, 2019.

Address for reprints: Kimihiro Shimizu, MD, PhD, Division of General Thoracic Surgery, Integrative Center of General Surgery, Gunma University Hospital, 3-39-22 Showa-machi, Maebashi, Gunma, 371-8511, Japan (E-mail: kmshimizu@gmail. com).

$0022-5223 / \$ 36.00$

Copyright () 2019 by The American Association for Thoracic Surgery https://doi.org/10.1016/j.jtcvs.2018.12.075 

Abbreviations and Acronyms
ACT $=$ adjuvant chemotherapy
$\mathrm{CEA}=$ carcinoembryonic antigen
$\mathrm{CI}=$ confidence interval
$\mathrm{CRC}=$ colorectal cancer
$\mathrm{DFS}=$ disease-free survival
$\mathrm{HR}=$ hazard ratio
OS = overall survival
$\mathrm{PM}=$ pulmonary metastasis

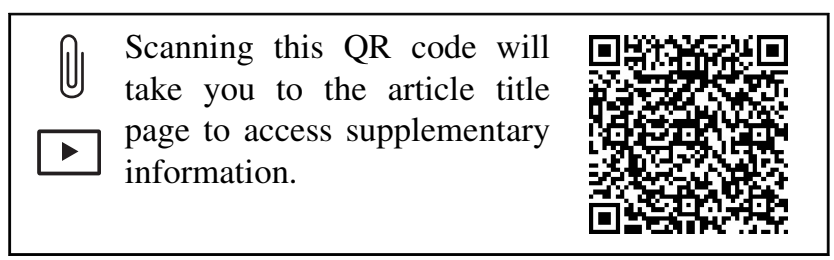

The most common sites of metastasis from colorectal adenocarcinoma are the liver and lung. Hepatic metastases occur in $8 \%$ to $30 \%$ of patients after curative resection of colorectal cancer (CRC), and pulmonary metastases (PMs) occur in $5 \%$ to $20 \%$ of patients. ${ }^{1-3}$
Surgical resection is considered to be the most effective treatment for hepatic metastases from CRC and has produced a 5-year survival of $25 \%$ to $58 \%{ }^{4-9} \mathrm{PMs}$ were previously thought to be incurable and were primarily treated with systemic chemotherapy. However, many surgeons have performed pulmonary metastasectomies in selected patients, with reported 5-year survival ranging from $27 \%$ to $68 \%{ }^{10-14}$ Recently, patients with histories of completely resected hepatic metastases have more widely received pulmonary metastasectomies, although no consensus is available on identifying patients most likely to benefit from sequential pulmonary metastasectomy among those with histories of completely resected hepatic metastases. ${ }^{15-23}$

The aim of this study was to clarify the long-term outcomes of patients who underwent sequential curative hepatic followed by pulmonary metastasectomies and to identify factors affecting their survival, based on the data from a large population of patients who underwent metastasectomy of PMs from CRC at 46 Japanese institutions.

\section{PATIENTS AND METHODS \\ Patients}

We retrospectively reviewed the medical records of patients who underwent metastasectomies of PMs from CRC at 46 Japanese institutions from January 2004 to December 2008. This period was selected because

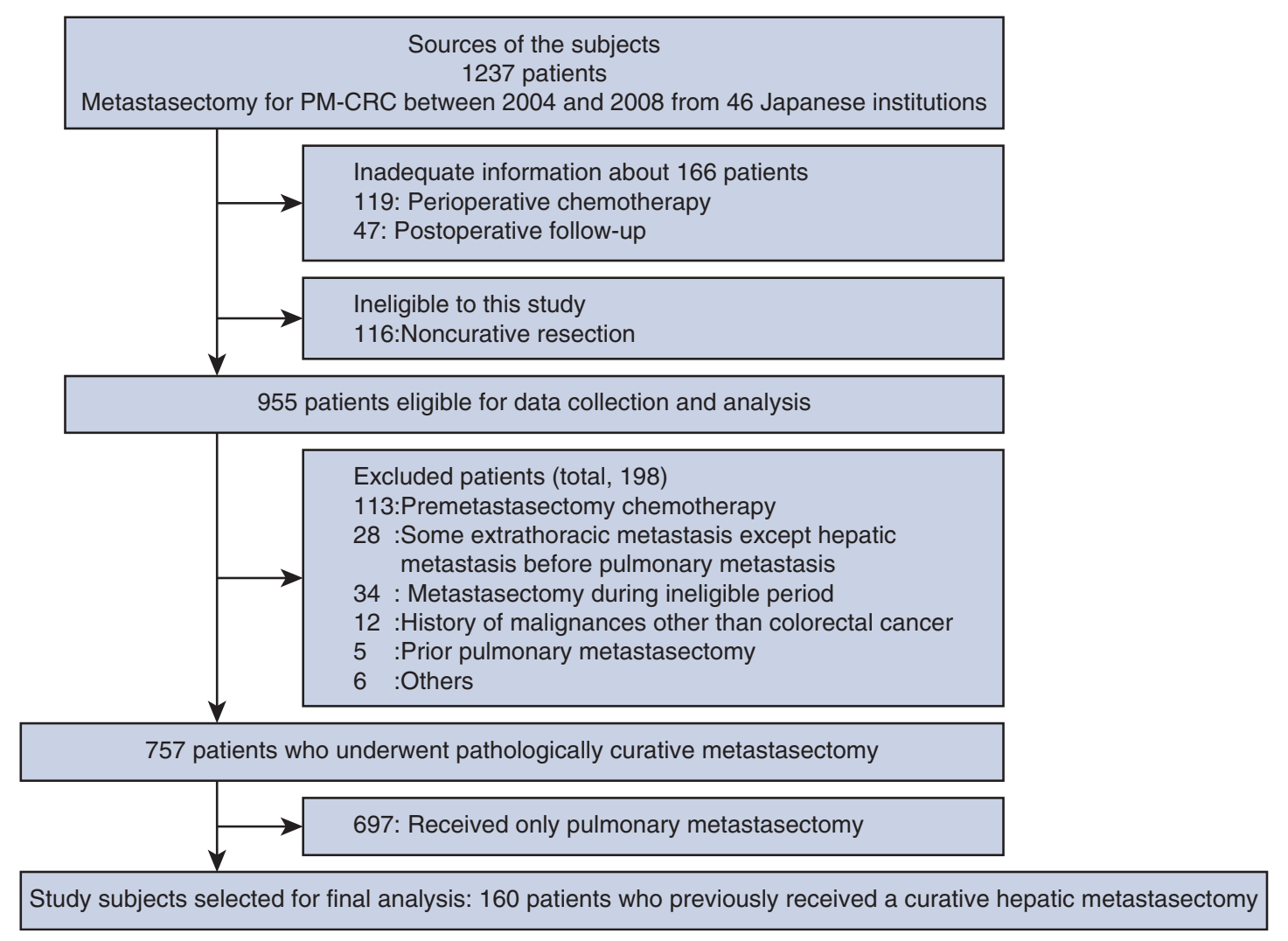

FIGURE 1. Flowchart of patient selection for analyses. $P M-C R C$, Pulmonary metastasis from colorectal cancer. 
5-fluorouracil with leucovorin plus irinotecan or oxaliplatin was approved for metastatic CRC in 2004 in Japan. Although indications and procedures for pulmonary metastasectomy varied by surgeons and institutions, metastasectomy was generally considered suitable in patients for whom (1) all pulmonary lesions are considered to be resectable; (2) hepatic metastasis has been curatively treated by hepatic metastasectomy; and (3) the expected surgical procedure can be tolerated. Inclusion criteria for this study were (1) no prior metastasectomy for PM; (2) pulmonary metastasectomy performed with curative intent for synchronous or simultaneous lesions with the primary tumor or hepatic metastases; (3) pathological confirmation of the resected lesions as metastases from CRC; and (4) metastasectomy with pathologically confirmed complete resection. Patients with extrathoracic lesions (other than hepatic metastasis) were excluded, even if those lesions had been treated with curative intent before hepatic or pulmonary metastasectomy. Hepatic and pulmonary metastases were considered simultaneous when diagnosed less than 3 months apart and sequential when diagnosed more than 3 months apart. Patients with PMs from appendix cancer or anal cancer were also excluded. Because this is a retrospective study, indications for postpulmonary metastasectomy adjuvant chemotherapy (ACT), hepatic resection procedures, and follow-up intervals after treatment also varied by institution. However, most recurrences were assessed with respect to the follow-up recommendation after primary tumor resection in the clinical guideline of Japanese Society for Cancer of the Colon and Rectum. ${ }^{24}$ Briefly, this entailed interviews and examinations, including tumor markers, every 3 months after initial CRC surgery for 3 years and then every 6 months. The cutoff date for our analysis data was August 31, 2013. This study was approved by the institutional review board of each participating institution.

\section{Data Collection}

All patients who fulfilled these criteria in participating institutions were registered. Clinical data were collected on prespecified case report forms that covered patients' demographic information, primary disease status, ACT after primary CRC resection, premetastasectomy status, details of metastasectomies, pathological findings of resected PMs, ACT after pulmonary metastasectomy, and prognosis.

\section{Statistical Analysis}

Overall survival (OS) was defined as the time between the date of pulmonary metastasectomy and the date of death from any cause. Patients who were alive at last follow-up were censored from the analysis at that time, regardless of disease status. Disease-free survival (DFS) was defined as the time between the date of pulmonary metastasectomy and the date of the first detection of recurrence or death. Patients who did not experience recurrence or death were censored at the date of last follow-up. Survival was estimated with the Kaplan-Meier method and compared with the log-rank test. Cox models were used for univariable and multivariable survival analyses. Variables for which the $P$ value was less than .1 in univariable analysis and previously reported prognostic factors were included in the multivariable analysis.

\section{RESULTS \\ Patients}

We collected case report forms of 1237 patients who underwent pulmonary metastasectomies. After evaluation by a central review board, 955 patients were judged to be suitable for analysis (Figure 1). We excluded 116 patients who underwent noncurative resection before data collection. We also excluded 198 patients from the final analysis, including 113 who underwent preoperative chemotherapy for pulmonary metastasis (PM) (because we could not
TABLE 1. Patient characteristics

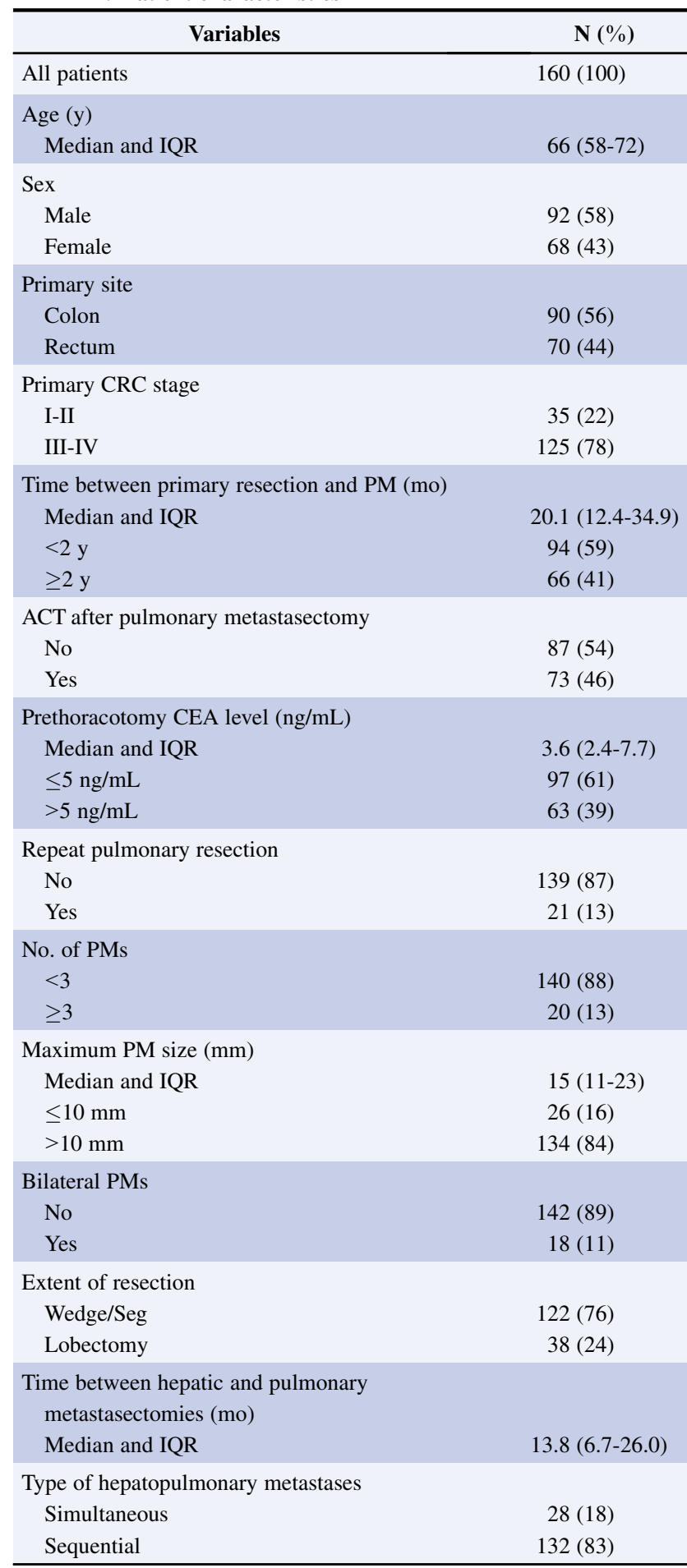

$A C T$, Adjuvant chemotherapy; $C E A$, carcinoembryonic antigen; $C T$, chemotherapy $C R C$, colorectal cancer; $I Q R$, interquartile range; $P M$, pulmonary metastasis; Wedge/seg, wedge resection or segmentectomy. Simultaneous denotes both hepatic and pulmonary metastases found within $3 \mathrm{mo}$.

adjust substantial differences in background characteristics, such as regimen, duration, and objective of chemotherapy) (Figure 1). We then reviewed the remaining 757 patients 


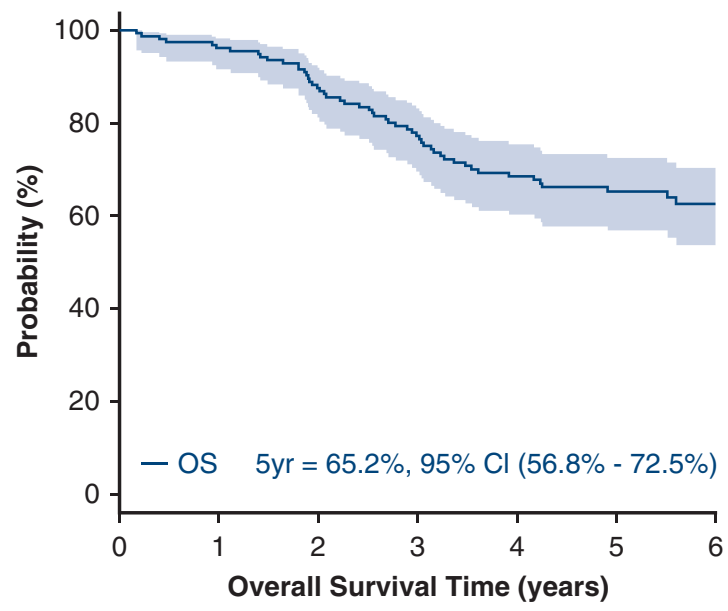

Number at risk

A

$\begin{array}{lllllll}160 & 149 & 130 & 109 & 90 & 65 & 34\end{array}$

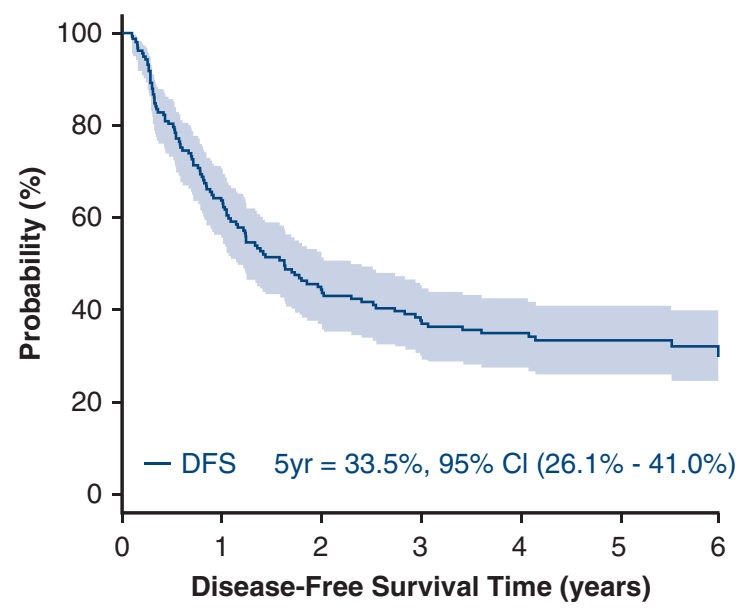

Number at risk

B $\begin{array}{lllllll}160 & 99 & 70 & 57 & 47 & 33 & 14\end{array}$

FIGURE 2. Kaplan-Meier curves and $95 \%$ CIs of OS (A) and DFS (B) after resection of pulmonary metastases from CRC. OS, Overall survival; $C I$, confidence interval; DFS, disease-free survival.

who underwent pathologically curative metastasectomies and extracted patients who previously underwent hepatic metastasectomies and then pulmonary metastasectomies $(\mathrm{n}=160)$.

Table 1 shows the background information of 160 patients, who underwent sequential curative hepatic and pulmonary metastasectomies, analyzed in this study. Their median age at the time of pulmonary metastasectomy was 66 years (IQR, 58-72); 58\% were male, and $44 \%$ had primary tumors sited in the rectum. The median time between primary resection and PM was 20.1 months (IQR, 12.434.9). PMs were solitary in $73 \%$ of patients; $18 \%$ had simultaneously diagnosed hepatic and pulmonary metastases; $39 \%$ had high ( $>5 \mathrm{ng} / \mathrm{mL}$ ) prethoracotomy carcinoembryonic antigen (CEA) levels; $76 \%$ had PMs removed by wedge resections or segmentectomies.

\section{Outcomes}

Death after pulmonary metastasectomy was observed in 55 patients $(34 \%)$. Figure 2 shows the Kaplan-Meier survival curves. The 5-year OS was $65.2 \%$ (95\% confidence interval $[\mathrm{CI}], 56.8-72.5)$, with a median follow-up of 64 months (censored case, interquartile range, 52-75; Figure 2, A). Ninety-eight patients $(61 \%)$ experienced recurrences. Pulmonary was the most common site of single-organ recurrence $(\mathrm{n}=35 ; 22 \%)$, followed by the liver $(\mathrm{n}=28 ; 18 \%)$ (Table 2$)$. The 5 -year DFS was $33.5 \%$ (95\% CI, 26.1-41.0; Figure 2, B). The simultaneous and sequential groups did not significantly differ in OS (hazard ratio [HR], $1.03 ; 95 \% \mathrm{CI}, 0.50-2.10 ; P=.99$ ) or DFS (HR, 1.03; 95\% CI, 0.50-2.10; $P=.52$ ) (Figure E1).

\section{Prognostic Factors}

The results of univariable and multivariable analyses for patients' background factors and outcomes are detailed in Tables 3 and 4 . We included the factors that were significant in univariable analysis and reported prognostic factors such as the number of PMs and ACT after pulmonary metastasectomy to variables for multivariable analysis. Multivariable analysis revealed that only prethoracotomy serum CEA level greater than $5 \mathrm{ng} / \mathrm{mL}$ was significantly associated

TABLE 2. Recurrence pattern after pulmonary metastasectomy

\begin{tabular}{lc}
\hline \multicolumn{1}{c}{ Variable } & $\mathbf{N}(\%)$ \\
\hline All patients & $160(100.0)$ \\
All recurrences & $98(61.3)$ \\
Single-site recurrence & \\
$\quad$ Lung & $35(21.9)$ \\
Liver & $28(17.5)$ \\
Abdominal cavity & $6(3.8)$ \\
Bone & $3(1.9)$ \\
Brain & $3(1.9)$ \\
Multisite recurrence & \\
Lung + liver & $11(6.9)$ \\
Lung + other* & $5(3.1)$ \\
Liver + other $\dagger$ & $3(1.9)$ \\
Primary site + brain & $1(0.6)$ \\
Brain + bone & $1(0.6)$ \\
Unknown & $2(1.3)$ \\
No recurrence & $62(38.8)$ \\
\hline *Adrenal gland, primary site + skin, bone, brain + bone + kidney. $\dagger$ Brain, stomach, \\
chest wall.
\end{tabular}


TABLE 3. Univariable and multivariable analyses of overall survival

\begin{tabular}{|c|c|c|c|c|}
\hline & \multicolumn{2}{|c|}{ Univariable } & \multicolumn{2}{|c|}{ Multivariable } \\
\hline & HR $(95 \%$ CI $)$ & $P$ & HR $(95 \%$ CI) & $P$ \\
\hline \multicolumn{5}{|l|}{ Age } \\
\hline \multicolumn{5}{|l|}{$<65 \mathrm{y}$} \\
\hline$\geq 65 \mathrm{y}$ & $1.62(0.94-2.80)$ & .082 & $1.81(1.01-3.24)$ & .045 \\
\hline \multicolumn{5}{|l|}{ Sex } \\
\hline Male & $1.08(0.63-1.85)$ & .772 & & \\
\hline \multicolumn{5}{|l|}{ Female } \\
\hline \multicolumn{5}{|l|}{ Primary site } \\
\hline \multicolumn{5}{|l|}{ Colon } \\
\hline Rectum & $1.75(1.03-2.97)$ & .040 & $1.73(1.00-2.98)$ & .050 \\
\hline \multicolumn{5}{|c|}{ Primary CRC stage } \\
\hline \multicolumn{5}{|c|}{ I-II } \\
\hline III-IV & $0.82(0.44-1.53)$ & .528 & & \\
\hline \multicolumn{5}{|c|}{ Prethoracotomy CEA } \\
\hline \multicolumn{5}{|c|}{$\leq 5 \mathrm{ng} / \mathrm{mL}$} \\
\hline$>5 \mathrm{ng} / \mathrm{mL}$ & $2.20(1.30-3.74)$ & .004 & $2.01(1.16-3.47)$ & .012 \\
\hline \multicolumn{5}{|l|}{ Extent of PM } \\
\hline \multicolumn{5}{|l|}{ Unilateral } \\
\hline Bilateral & $1.44(0.71-2.95)$ & .316 & & \\
\hline \multicolumn{5}{|c|}{ The number of PMs, $n$} \\
\hline \multicolumn{5}{|c|}{$<3$} \\
\hline$\geq 3$ & $1.37(0.69-2.73)$ & .366 & $1.59(0.76-3.30)$ & .216 \\
\hline \multicolumn{5}{|c|}{ Maximum PM size } \\
\hline \multicolumn{5}{|c|}{$\leq 10 \mathrm{~mm}$} \\
\hline$>10 \mathrm{~mm}$ & $2.72(0.98-7.51)$ & .054 & $1.02(0.99-1.05)$ & .224 \\
\hline \multicolumn{5}{|c|}{ ACT after pulmonary metastasectomy } \\
\hline \multicolumn{5}{|c|}{ No } \\
\hline Yes & $0.79(0.46-1.34)$ & .376 & $0.85(0.49-1.48)$ & .569 \\
\hline \multicolumn{5}{|c|}{ Extent of pulmonary resection } \\
\hline \multicolumn{5}{|l|}{ Wedge/Seg } \\
\hline Lobectomy & $1.29(0.70-2.36)$ & .416 & & \\
\hline \multicolumn{5}{|c|}{ Time between primary resection and hepatic metastasectomy } \\
\hline \multicolumn{5}{|l|}{$<1 \mathrm{y}$} \\
\hline$\geq 1 \mathrm{y}$ & $0.86(0.44-1.66)$ & .651 & & \\
\hline \multicolumn{5}{|c|}{ Hepatopulmonary met timing } \\
\hline \multicolumn{5}{|l|}{ Sim } \\
\hline Seq & $1.03(0.50-2.10)$ & .944 & & \\
\hline
\end{tabular}

Bold denotes statistically significant. $H R$, Hazard ratio; $C I$, confidence interval; $C R C$, colorectal cancer; $C E A$, carcinoembryonic antigen; $A C T$, adjuvant chemotherapy; $P M$, pulmonary metastasis; Wedge/seg, wedge resection or segmentectomy; met, metastases; Sim, simultaneous (both hepatic and pulmonary metastases found within 3 mo); Seq, sequential.

with both shorter OS (HR, 2.01; 95\% CI, 1.16-3.47; $P=.012$ ) and DFS (HR, 2.10; 95\% CI, 1.41-3.12; $P<.001)$. Five-year OS of normal versus high prethoracotomy CEA levels was $76.4 \%$ versus $47.6 \%$, respectively, and 5-year DFS was $40.7 \%$ versus $22.4 \%$, respectively (Figure 3). There was a trend that patients with a higher serum level of prethoracotomy CEA showed worse survival (Figure E2). Age (HR, 1.81; 95\% CI, 1.01-3.24; $P=.045$ ) was significantly associated with shorter OS (Table 3 ). Male sex (HR, $1.68 ; 95 \%$ CI, 1.12-2.52; $P=.013)$ was associated with shorter DFS (Table 4).

\section{DISCUSSION}

This study demonstrated that clinical outcomes of patients who underwent curative hepatic metastasectomy followed by pulmonary metastasectomy were OS of $65.2 \%$ and DFS of $33.5 \%$. These data seemed to be better than previous reports of OS ranging from $11 \%$ to $54 \%$ and DFS ranging from $13 \%$ to $28 \%,{ }^{15-23}$ although we limited them to patients with R0. Most previous studies investigated small numbers of patients or used time frames longer than 10 years to obtain adequate numbers of patients. ${ }^{15-21,23}$ Therefore, it is unclear whether those previous reports 
TABLE 4. Univariable and multivariable analyses of disease-free survival

\begin{tabular}{|c|c|c|c|c|}
\hline & \multicolumn{2}{|c|}{ Univariable } & \multicolumn{2}{|c|}{ Multivariable } \\
\hline & HR $(95 \%$ CI $)$ & $P$ & HR $(95 \%$ CI $)$ & $P$ \\
\hline \multicolumn{5}{|l|}{ Age } \\
\hline \multicolumn{5}{|l|}{$<65 \mathrm{y}$} \\
\hline$\geq 65 \mathrm{y}$ & $1.46(0.99-2.16)$ & .057 & $1.49(0.99-2.2) 4$ & .057 \\
\hline \multicolumn{5}{|l|}{ Sex } \\
\hline Male & $1.50(1.01-2.23)$ & .043 & $1.68(1.12-2.52)$ & .013 \\
\hline \multicolumn{5}{|l|}{ Female } \\
\hline \multicolumn{5}{|l|}{ Primary site } \\
\hline \multicolumn{5}{|l|}{ Colon } \\
\hline Rectum & $1.30(0.89-1.91)$ & .177 & & \\
\hline \multicolumn{5}{|l|}{ Primary stage } \\
\hline \multicolumn{5}{|l|}{ I-II } \\
\hline III-IV & $1.00(0.63-1.60)$ & .978 & & \\
\hline \multicolumn{5}{|c|}{ Prethoracotomy CEA } \\
\hline \multicolumn{5}{|c|}{$\leq 5 \mathrm{ng} / \mathrm{mL}$} \\
\hline$>5 \mathrm{ng} / \mathrm{mL}$ & $1.96(1.33-2.87)$ & .001 & $2.10(1.41-3.12)$ & $<.001$ \\
\hline \multicolumn{5}{|l|}{ Extent of PM } \\
\hline \multicolumn{5}{|l|}{ Unilateral } \\
\hline Bilateral & $1.55(0.90-2.68)$ & .116 & & \\
\hline \multicolumn{5}{|l|}{ No. of PMs, $n$} \\
\hline \multicolumn{5}{|l|}{$<3$} \\
\hline$\geq 3$ & $1.57(0.93-2.63)$ & .091 & $1.72(1.00-2.98)$ & .051 \\
\hline \multicolumn{5}{|c|}{ Maximum PM size } \\
\hline \multicolumn{5}{|c|}{$\leq 10 \mathrm{~mm}$} \\
\hline$>10 \mathrm{~mm}$ & $1.17(0.69-2.00)$ & .559 & & \\
\hline \multicolumn{5}{|c|}{ ACT after pulmonary metastasectomy } \\
\hline \multicolumn{5}{|c|}{ No } \\
\hline Yes & $1.08(0.74-1.58)$ & .697 & $1.06(0.72-1.56)$ & .778 \\
\hline \multicolumn{5}{|c|}{ Extent of pulmonary resection } \\
\hline \multicolumn{5}{|l|}{ Wedge/seg } \\
\hline Lobectomy & $1.34(0.86-2.07)$ & .195 & & \\
\hline \multicolumn{5}{|c|}{ Time between primary resection and hepatic metastasectomy } \\
\hline \multicolumn{5}{|c|}{$<1 \mathrm{y}$} \\
\hline$\geq 1 \mathrm{y}$ & $0.79(0.50-1.26)$ & .324 & & \\
\hline \multicolumn{5}{|c|}{ Hepatopulmonary met timing } \\
\hline \multicolumn{5}{|c|}{ Sim } \\
\hline Seq & $0.86(0.54-1.37)$ & .517 & & \\
\hline
\end{tabular}

Bold denotes statistically significant. $H R$, Hazard ratio; $C I$, confidence interval; $C E A$, carcinoembryonic antigen; $P M$, pulmonary metastasis; $A C T$, adjuvant chemotherapy; Wedge/seg, wedge resection or segmentectomy; met, metastases; Sim, simultaneous (both hepatic and pulmonary metastases found within 3 mo); Seq, sequential.

reflect current practice and their patient cohort of pulmonary metastasectomy after curative hepatic metastasectomy is identical to this study. The present study is a multicenter study of patients who underwent pulmonary metastasectomy with a curative intent over a relatively narrow period of 5 years between 2004 and 2008. This period was the first 5 years after approval of current standard chemotherapy for CRC such as 5-fluorouracil with leucovorin plus irinotecan or oxaliplatin in Japan. We also had a long follow-up period (median, 64 months) to provide the latest long-term outcomes. Our study shows the results of current pulmonary metastasectomy practices in patients who previously underwent hepatic metastasectomy with similar backgrounds. However, because we selected only patients with curative resections, more than $70 \%$ had solitary pulmonary metastases, which could lead to better outcomes.

Recently, the LiverMetSurvey, a prospective international registry of patients undergoing surgery for colorectal hepatic metastases at 253 centers in 66 countries, reported that among patients with simultaneous pulmonary and hepatic metastases (ie, identified within 3 months), those 

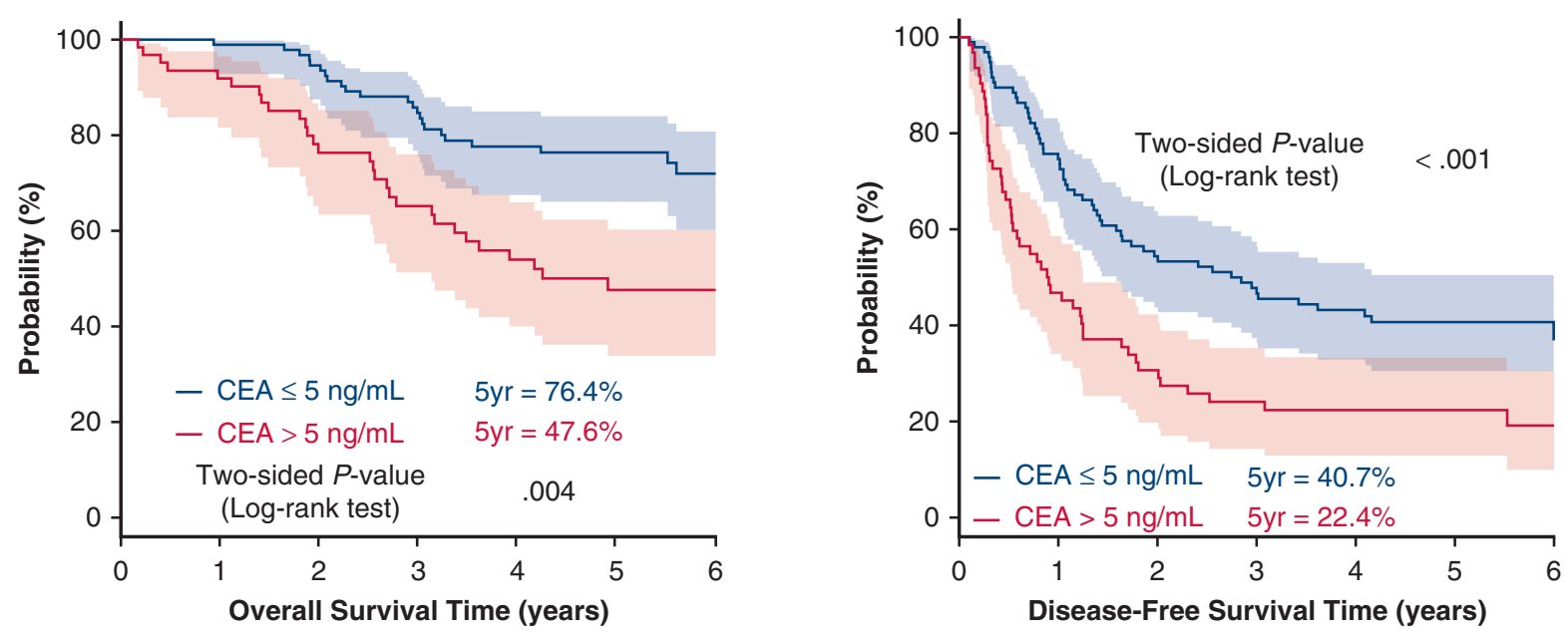

\section{Number at risk}

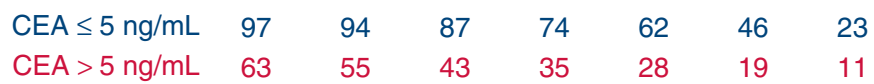

A

FIGURE 3. Kaplan-Meier curves and $95 \%$ CIs of OS (A) and DFS (B) after resection of pulmonary metastases from CRC according to serum levels of CEA (cutoff value $5 \mathrm{ng} / \mathrm{mL}$ ). CEA, Carcinoembryonic antigen.

who underwent resections of both pulmonary and hepatic metastases had a higher 5-year OS $(40.7 \%)$ than those who only underwent hepatic metastasectomies $(9.4 \%){ }^{22}$ The 5-year OS of patients with simultaneous pulmonary and hepatic metastases who underwent both metastasectomies was slightly lower $(40.7 \%)$ than for patients with isolated hepatic metastases who underwent hepatic metastasectomy $(50.0 \%) .{ }^{22}$ We do not have a clear explanation for the relatively high 5-year OS of simultaneous patients in our study $(62.1 \%$; Figure E1, A) compared with the LiverMetSurvey study, except that the number of our patients was small. The LiverMetSurvey registry data and our results suggest that the presence of resectable hepatic metastases or history of curative hepatic metastasectomy is not a contraindication to pulmonary metastasectomy.

Until now, few studies have reported on prognostic factors for patients with CRC who underwent curative resections of both hepatic and pulmonary metastases. Brouquet and colleagues ${ }^{20}$ reported that serum CEA levels before resection of hepatic metastases and primary rectal tumors were associated with OS in patients who had undergone resections of both hepatic and pulmonary metastases, although the impact of CEA on DFS was not mentioned. Kim and colleagues ${ }^{23}$ reported that the time between primary resection and PM less than 12 months and multiple PMs were independent prognostic factors associated with worse OS and DFS, although CEA was not included in their analyzed variables. In our study, high prethoracotomy serum CEA level was an independent prognostic factor associated with both worse OS and DFS, which is also reportedly prognostic for isolated PM from CRC in many studies. $^{2,25,26}$ This probably reflects the total tumor burden before pulmonary metastasectomy.

This study identifies, for the first time, high prethoracotomy serum CEA level as an unfavorable prognostic factor for both OS and DFS in these patients, which indicates its clinical utility in determining treatment strategy (Figure 4). A history of curative hepatic metastasectomy should not be considered a contraindication for pulmonary metastasectomy in patients with CRC, especially if the prethoracotomy serum CEA level is within normal range. However, the benefit of the systemic chemotherapy before or after pulmonary metastasectomy for patients with high prethoracotomy CEA level is unknown. In the future, the efficacy of perioperative or preoperative chemotherapy to these stratifying patients should be evaluated prospectively. In the present study, age was found to predict shorter OS and male sex was found to predict shorter DFS, which have also been reported in previous studies on pulmonary metastasectomy in patients with CRC. ${ }^{14,15,18,27}$ The prognostic and clinical significance of these factors with respect to OS or DFS should be evaluated further in other large-scale studies.

\section{Study Limitations}

This study has some limitations. First, we excluded patients with noncurative resection, which could cause a significant selection bias. We initially tried to demonstrate the survival and prognostic factors in patients after complete resection of both hepatic and pulmonary metastases. However, complete resection cannot always be achieved in all patients. This biased our study and could not reflect clinical reality. Indications for metastasectomy and ACT 


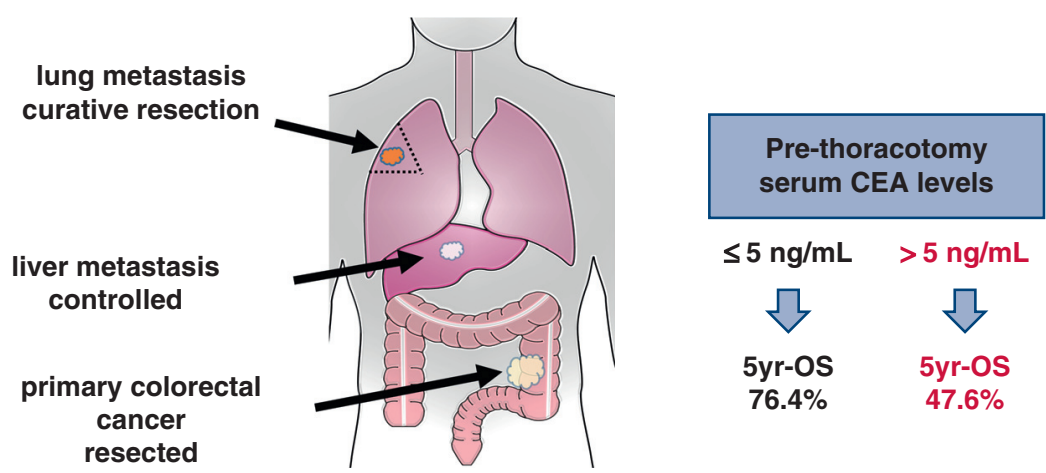

FIGURE 4. Graphic schema of OS in patients who underwent both hepatic and pulmonary metastasectomies. Five-year OS of the patients with normal prethoracotomy CEA levels was significantly higher than that of the patients with high prethoracotomy CEA levels (76.4\% vs $47.6 \%)$. CEA, Carcinoembryonic antigen; $O S$, overall survival.

differed among institutions because of the retrospective nature of this study, which might influence clinical outcomes. Estimation of DFS was not as precise as it would be in a prospective study. Details of hepatic metastases (eg, number or size) were not available in the database but might affect disease progression. ${ }^{14}$ Although we followed up the patients for relatively long periods, the median follow-up period (64 months) was not sufficient and the patient cohort was slightly dated. We also excluded the patients with perioperative or preoperative chemotherapy.

\section{CONCLUSIONS}

On the basis of these favorable survival results, we recommend pulmonary metastasectomy in patients with a resectable PM from CRC, even if they previously received a curative hepatic metastasectomy (Video 1).

\section{Conflict of Interest Statement}

N.B. has received grants and personal fees from Taiho Pharmaceutical Company and Ono Pharmaceutical Company, and personal fees from Chugai Pharmaceutical Company

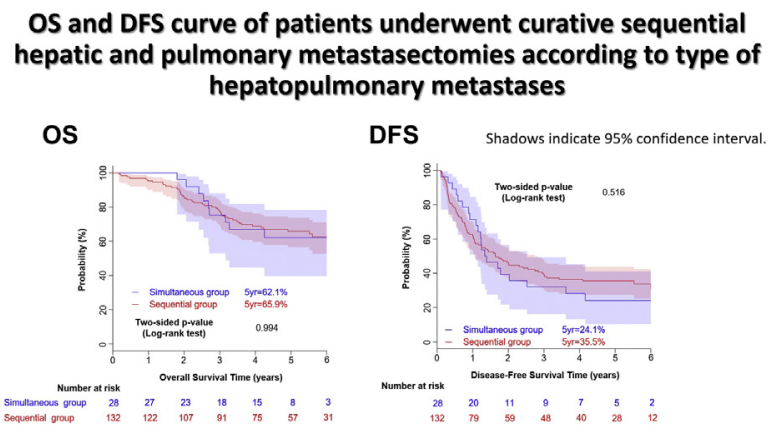

Simultaneous group: both hepatic and pulmonary metastases found within 3 months

VIDEO 1. Outcomes and prognostic factors after pulmonary metastasectomy in patients with CRC with previously or simultaneously resected hepatic metastases. Video available at: https://www.jtcvs.org/ article/S0022-5223(19)30002-9/fulltext. and Eli Lilly and Company. M.T. has received grants and personal fees from AstraZeneca, Boehringer Ingelheim, Bristol-Myers Squibb Company, Chugai Pharmaceutical Company, Kyowa Hakko Kirin Company, Ono Pharmaceutical Company, and Eli Lilly and Company, a grant from Novartis Pharmaceuticals Corporation, and personal fees from Covidien, Merck and Company, and Taiho Pharmaceutical Company. All other authors have nothing to disclose with regard to commercial support.

The authors thank Mizuki Aida for data preparation and all of the following participating investigators for data collection: Takamichi Igarash, Seshiru Nakazawa, Gunma University Graduate School of Medicine; Tomoyuki Hishida, National Cancer Center East; Yasuhisa Ohde, Shizuoka Cancer Center; Yukinori Sakao, Aichi Cancer Center; Katsuo Yoshiya, Niigata Cancer Center; Kotaro Kameyama, Kurashiki Central Hospital; Hirofumi Adachi, Hokkaido Cancer Center; Kazu Shiomi, Kitasato University School of Medicine; Masato Kanzaki, Tokyo Women's Medical University; Masahiro Yoshimura, Hyogo Cancer Center; Motoki Matsuura, Hiroshima City Hospital; Yoshinobu Hata, Toho University School of Medicine; Fengshi Chen, Kyoto University Graduate School of Medicine; Kazuo Yoshida, Shinshu University School of Medicine; Hidefumi Sasaki, Nagoya City University Graduate School of Medical Sciences; Takehisa Hashimoto, Niigata University Graduate School of Medical; Atsushi Fujita, Gunma Cancer Center; Meinoshin Okumura, Osaka University Graduate School of Medicine; Kazuhito Funai, Hamamatsu University School of Medicine; Satoshi Shiono, Yamagata Prefectural Central Hospital; Hisatoshi Asano, Jikei University School of Medicine; Makoto Suzuki, Kumamoto University Hospital; Yuji Shiraishi, Fukujuji Hospital; Mitsuo Nakayama, Saitama Medical University medical center; Shunsuke Yamada, Tokai University Hachioji Hospital; Eishin Hoshi, Saitama Cardiovascular and Respiratory Center; Nobuhiro Yamazaki, Saitama Medical University International Medical Center; Toshihiro Matsuo, Kurume University School of Medicine; Hideki Miyazawa, Toyama Prefectural Central Hospital; Yukio Sato, University of Tsukuba; Motoshi Takao, Mie University School of Medicine; Haruhiko Nakamura, St. Marianna University School of Medicine; Haruhiko Nakayama, Kanagawa Cancer Center; Takehiro Watanabe, Nishi-Niigata 
Chuo National Hospital; Hiroyuki Suzuki, Fukushima Medical University; Masafumi Kataoka, Okayama Saiseikai General Hospital; Yoshio Tsunezuka, Ishikawa Prefectural Central Hospital; Shinji Akamine, Oita Prefectural Hospital; Mitsutaka Kadokura, Showa University School of Medicine; and Masao Nakata, Kawasaki Medical School.

\section{References}

1. Scheele J, Stangl R, Altendorf-Hofmann A. Hepatic metastases from colorectal carcinoma: impact of surgical resection on the natural history. Br J Surg. 1990; 77:1241-6.

2. Inoue M, Ohta M, Iuchi K, Matsumura A, Ideguchi K, Yasumitsu T, et al. Benefits of surgery for patients with pulmonary metastases from colorectal carcinoma. Ann Thorac Surg. 2004;78:238-44.

3. McCormack PM, Burt ME, Bains MS, Martini N, Rusch VW, Ginsberg RJ. Lung resection for colorectal metastases. 10-year results. Arch Surg. 1992;127: 1403-6.

4. Abdalla EK, Vauthey JN, Ellis LM, Ellis V, Pollock R, Broglio KR, et al. Recurrence and outcomes following hepatic resection, radiofrequency ablation, and combined resection/ablation for colorectal liver metastases. Ann Surg. 2004; 239:818-25.

5. Bradley AL, Chapman WC, Wright JK, Marsh JW, Geevarghese S, Blair KT, et al. Surgical experience with hepatic colorectal metastasis. Am Surg. 1999; 65:560-6.

6. Doci R, Gennari L, Bignami P, Montalto F, Morabito A, Bozzetti F. One hundred patients with hepatic metastases from colorectal cancer treated by resection: analysis of prognostic determinants. Br J Surg. 1991:78:797-801.

7. Fong Y, Fortner J, Sun RL, Brennan MF, Blumgart LH. Clinical score for predicting recurrence after hepatic resection for metastatic colorectal cancer: analysis of 1001 consecutive cases. Ann Surg. 1999;230:309-18.

8. Ohlsson B, Stenram U, Tranberg KG. Resection of colorectal liver metastases: 25-year experience. World J Surg. 1998;22:268-76.

9. Adam R, de Haas RJ, Wicherts DA, Vibert E, Salloum C, Azoulay D, et al. Concomitant extrahepatic disease in patients with colorectal liver metastases: when is there a place for surgery? Ann Surg. 2011;253:349-59.

10. Pfannschmidt J, Dienemann H, Hoffmann H. Surgical resection of pulmonary metastases from colorectal cancer: a systematic review of published series. Ann Thorac Surg. 2007:84:324-38.

11. Fiorentino F, Hunt I, Teoh K, Treasure T, Utley M. Pulmonary metastasectomy in colorectal cancer: a systematic review and quantitative synthesis. $J$ R Soc Med. 2010;103:60-6.

12. Salah S, Watanabe K, Welter S, Park JS, Park JW, Zabaleta J, et al. Colorectal cancer pulmonary oligometastases: pooled analysis and construction of a clinical lung metastasectomy prognostic model. Ann Oncol. 2012;23:2649-55.

13. Gonzalez M, Poncet A, Combescure C, Robert J, Ris HB, Gervaz P. Risk factors for survival after lung metastasectomy in colorectal cancer patients: a systematic review and meta-analysis. Ann Surg Oncol. 2013;20:572-9.
14. Okumura T, Boku N, Hishida T, Ohde Y, Sakao Y, Yoshiya K, et al. Surgical outcome and prognostic stratification for pulmonary metastasis from colorectal cancer. Ann Thorac Surg. 2017;104:979-87.

15. Miller G, Biernacki P, Kemeny NE, Gonen M, Downey R, Jarnagin WR, et al. Outcomes after resection of synchronous or metachronous hepatic and pulmonary colorectal metastases. J Am Coll Surg. 2007;205:231-8.

16. Zabaleta J, Aguinagalde B, Fuentes MG, Bazterargui N, Izquierdo JM, Hernandez CJ, et al. Survival after lung metastasectomy for colorectal cancer: importance of previous liver metastasis as a prognostic factor. Eur J Surg Oncol. 2011:37:786-90.

17. Regnard JF, Grunenwald D, Spaggiari L, Girard P, Elias D, Ducreux M, et al. Surgical treatment of hepatic and pulmonary metastases from colorectal cancers. Ann Thorac Surg. 1998;66:214-8.

18. Nagakura S, Shirai Y, Yamato Y, Yokoyama N, Suda T, Hatakeyama K. Simultaneous detection of colorectal carcinoma liver and lung metastases does not warrant resection. J Am Coll Surg. 2001;193:153-60.

19. Kobayashi K, Kawamura M, Ishihara T. Surgical treatment for both pulmonary and hepatic metastases from colorectal cancer. J Thorac Cardiovasc Surg. 1999;118:1090-6.

20. Brouquet A, Vauthey JN, Contreras CM, Walsh GL, Vaporciyan AA, Swisher SG, et al. Improved survival after resection of liver and lung colorectal metastases compared with liver-only metastases: a study of 112 patients with limited lung metastatic disease. J Am Coll Surg. 2011;213:62-9.

21. Hattori N, Kanemitsu Y, Komori K, Shimizu Y, Sano T, Senda Y, et al. Outcomes after hepatic and pulmonary metastasectomies compared with pulmonary metastasectomy alone in patients with colorectal cancer metastasis to liver and lungs. World J Surg. 2013;37:1315-21.

22. Andres A, Mentha G, Adam R, Gerstel E, Skipenko OG, Barroso E, et al. Surgical management of patients with colorectal cancer and simultaneous liver and lung metastases. Br J Surg. 2015;102:691-9.

23. Kim S, Kim HK, Cho JH, Choi YS, Kim K, Kim J, et al. Prognostic factors after pulmonary metastasectomy of colorectal cancers: influence of liver metastasis. World J Surg Oncol. 2016;14:201.

24. Watanabe T, Itabashi M, Shimada Y, Tanaka S, Ito Y, Ajioka Y, et al. Japanese Society for Cancer of the Colon and Rectum (JSCCR) guidelines 2014 for treatment of colorectal cancer. Int J Clin Oncol. 2015;20:207-39.

25. Okumura S, Kondo H, Tsuboi M, Nakayama H, Asamura H, Tsuchiya R, et al. Pulmonary resection for metastatic colorectal cancer: experiences with 159 patients. J Thorac Cardiovasc Surg. 1996;112:867-74.

26. Saito Y, Omiya H, Kohno K, Kobayashi T, Itoi K, Teramachi M, et al. Pulmonary metastasectomy for 165 patients with colorectal carcinoma: a prognostic assessment. J Thorac Cardiovasc Surg. 2002;124:1007-13.

27. Kamiyoshihara M, Igai H, Kawatani N, Ibe T, Tomizawa N, Obayashi K, et al Lung metastasectomy for postoperative colorectal cancer in patients with a history of hepatic metastasis. Gen Thorac Cardiovasc Surg. 2014;62:314-20.

Key Words: pulmonary metastasis, colorectal cancer, CEA, hepatic metastasis, metastasectomy 


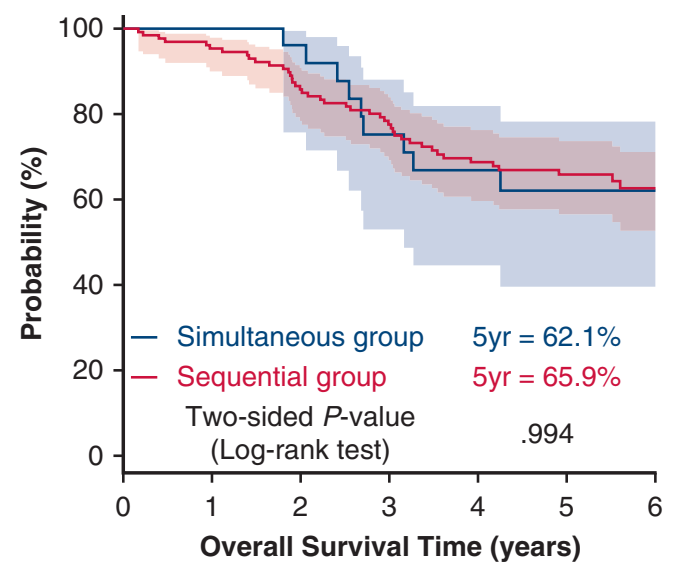

Number at risk

$\begin{array}{llllllll}\text { Simultaneous group } & 28 & 27 & 23 & 18 & 15 & 8 & 3\end{array}$

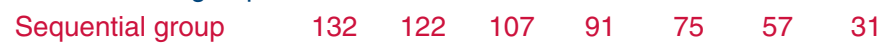

\section{A}

FIGURE E1. OS (A) and DFS (B) curves for patients after resection of pulmonary metastases who previously (sequential group) and simultaneously (simultaneous group) underwent curative hepatic metastasectomy. The 2 groups did not significantly differ.

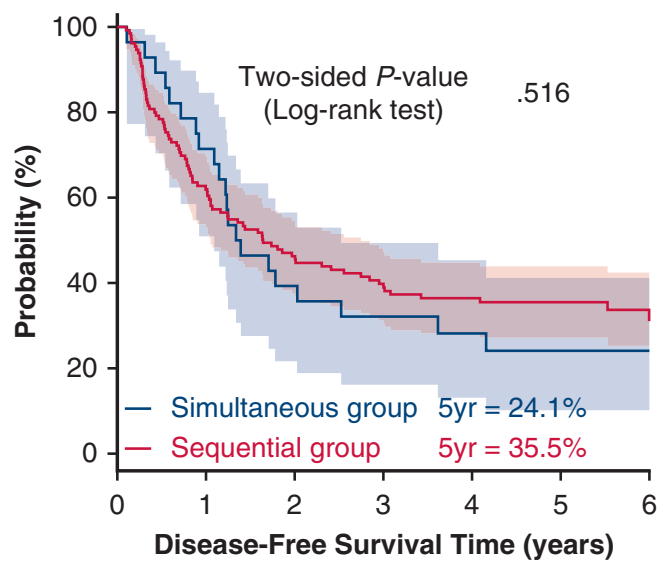

Number at risk

B

$\begin{array}{ccccccc}28 & 20 & 11 & 9 & 7 & 5 & 2 \\ 132 & 79 & 59 & 48 & 40 & 28 & 12\end{array}$
12

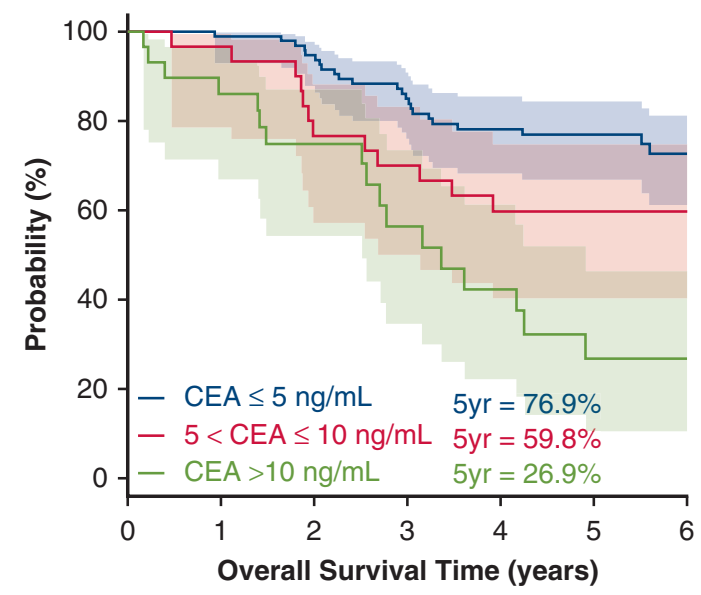

Number at risk

\begin{tabular}{|c|c|c|c|c|c|c|c|}
\hline$\leq 5 \mathrm{ng} / \mathrm{mL}$ & 99 & 96 & 89 & 76 & 64 & 48 & 25 \\
\hline 5.1 to $10 \mathrm{ng} / \mathrm{mL}$ & 32 & 29 & 23 & 21 & 17 & 12 & 7 \\
\hline$>10 \mathrm{ng} / \mathrm{mL}$ & 29 & 24 & 18 & 12 & 9 & 5 & 2 \\
\hline & \multicolumn{3}{|c|}{$\begin{array}{l}\text { Two-sided } P \text {-value } \\
\text { (Log-rank test) }\end{array}$} & $\leq 5 \mathrm{ng} / \mathrm{mL}$ & \multicolumn{3}{|c|}{5.1 to $10 \mathrm{ng} / \mathrm{mL}$} \\
\hline & \multicolumn{3}{|c|}{5.1 to $10 \mathrm{ng} / \mathrm{mL}$} & .137 & & & \\
\hline A & \multicolumn{3}{|c|}{$>10 \mathrm{ng} / \mathrm{mL}$} & $<.001$ & \multicolumn{3}{|c|}{.042} \\
\hline
\end{tabular}

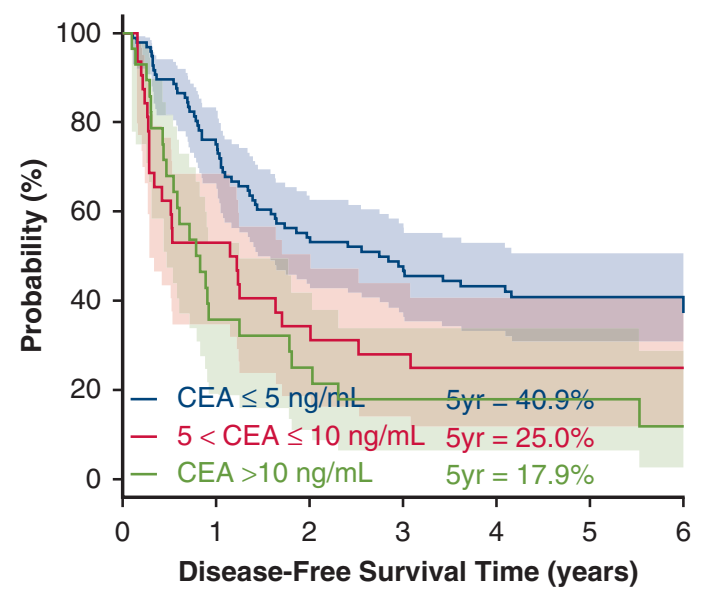

Number at risk sly (1) 